\title{
Influence of the main agrotechnical techniques of cultivation on the yield of plague seeds (Setaria Italica (L.) P. Beauv) in the Lower Volga Region
}

\author{
Tatiana Rodina*, Konstantin Kondakov, and Aleksandr Astashov \\ Russian Research and Design Institute of Sorghum and Maize «Rossorgo», 410050, 4, 1-st \\ Institutskiy proezd, Saratov, Russian Federation
}

\begin{abstract}
For the arid conditions of the Lower Volga region, plague is a promising forage crop. The article presents the results of assessing the study of the effect of the seeding rate and sowing methods on the yield of seeds of the plague variety Stachumi 3, which made it possible to identify the optimal option for obtaining the maximum yield. The study was carried out on the experimental field of the Federal State Budgetary Scientific Institution of the Russian Research Institute of Sorghum and Corn Rossorgo, which is located in the suburban microzone of the Saratov region and is geographically located in the southern part of the chernozem zone of the Lower Volga region. The climate of the region is sharply continental and dry. The soil of the experimental field is southern chernozem. The results obtained were confirmed by the analysis of variance of a two-factor experiment on the study of six gradations of factor A (seeding rate from 1.25 to 7.50 million pcs./ha) and three gradations of factor B (seeding method with row spacing 70,30 and $15 \mathrm{~cm}$ ), according to the data of which revealed significant differences in the influence of the seeding rate on the yield of plague seeds. On average, over four years of study (2013-2016), the highest yield in the experiment was obtained at a seeding rate of 1.25 million pcs./ha with a wide-row sowing method with a row spacing of $70 \mathrm{~cm}-2.13 \mathrm{t} / \mathrm{ha}$, when sowing the same the norm with a decrease in the width of the row spacing to $30 \mathrm{~cm}$, the yield decreased by $22.6 \%$. In the most favorable year in terms of moisture in 2013 (GTC = 1.7), the maximum yield in the experiment was obtained at a seeding rate of 2.50 million pcs./ha and amounted to $3.81 \mathrm{t} / \mathrm{ha}$. The tendency of decrease in the yield of plague seeds with an increase in the seeding rate has been established. The lowest yield in the experiment was obtained with an ordinary sowing method $(15 \mathrm{~cm})$ and a seeding rate of 7.50 million $\mathrm{pcs} . / \mathrm{ha}-0.36 \mathrm{t} / \mathrm{ha}$. The main share in the manifestation of the trait over the three years of study was made by factor A (seeding rate) and amounted to $77.6-80.7 \%$ of the total sum of squares, and in 2016 the share of the influence of this factor was $29.5 \%$ only. Factor B (sowing method) in 2013-2015 accounts for from $8.0 \%$ to $13.8 \%$, and in 2016 the share of the studied factor increased upto $62.1 \%$. The proportional participation of the interaction of $\mathrm{AB}$ factors varied insignificantly over the years of the study.
\end{abstract}

\footnotetext{
*Corresponding author: rodina008@mail.ru
} 


\section{Introduction}

Creation of a solid forage base for development of animal husbandry is the most important direction in carrying out scientific study in the field of crop production. Due to rise in prices for the main grain fodder crops (wheat, barley, oats, millet and others), it is necessary to search for less widespread crops that could partially or completely replace them in the composition of mixed fodders, not inferior in biological value and feed qualities to traditional crops $[1,2]$.

As noted by many researchers, E.A. Vertikova (2016), I.A. Donets (2019), M.K. Sadigov (2019), due to the complex of biological and economically valuable traits inherent in millet crops, plague is of interest in food and forage relations [3, 4, 5]. Plague Setaria italica (L.) P. Beauv is the world's oldest cereal characterized by high drought resistance, the homeland of which is Southeast Asia, which has become widespread in recent years as a fodder crop used for silage, hay, green mass and grain fodder. According to S. Sakamoto (1987), H. Darmency (2005), the cultivation of plague in East and Southeast Asia, where the bulk of varieties of this species is concentrated, is known long before our era, which is confirmed by botanical-geographical data and historical data, where it is widely used for food purposes (cereals, flour, bakery products), cultivated for grain, as well as fodder [6, 7]. In terms of biological characteristics and basic botanical characteristics, plague has much in common with millet [8]. In Russia, Western Europe, USA, South Africa, it is mainly cultivated for feed for poultry and cattle [9].

Plague is one of the promising crops for the Lower Volga region characterized by high productivity and ecological plasticity, valuable biochemical composition of grain and aboveground biomass, resistance to biotic and abiotic stressors, pests and diseases. This crop can be an alternative or raw material supplement to millet and sorghum forage. Plague is a thermophilic crop and has a relatively greater drought tolerance than, for example, corn [10].

Plague has a high breeding rate. According to the results of studies of domestic and foreign scientists, it has been proved that the yield of plague in production conditions is: aboveground biomass - 35.5-41.0 t/ha, hay - 9.0-9.9 t/ha, seeds - 4.6- $6.3 \mathrm{t} / \mathrm{ha}$. Vasilenko (2014) found that when sowing plague in a wide-row method with a row spacing of $45 \mathrm{~cm}$, the highest grain yield was obtained, productivity from one panicle increased in comparison with the usual row method $[11,12]$. As evidenced by the study results of Letuchiy (2009), when growing plague in the dry-steppe Trans-Volga region in single-species and joint crops for production of green forage, a high yield of aboveground biomass was obtained - 25.2$28.4 \mathrm{t} / \mathrm{ha}$, and the seed yield was $2.8-3.2 \mathrm{t} / \mathrm{ha}$ [13].

Cultivation of plague, as a universal crop in the climatic conditions of the Lower Volga region, is due to the fact that unfavorable winter weather conditions pose a difficult question for agricultural producers to choose agricultural crops for replanting the areas under winter crops so as to minimize losses in the shortage of food and feed grains. However, one of the main reasons for the weak introduction of plague into production is insufficient knowledge of the biological characteristics and agricultural techniques of cultivation in relation to the weather conditions of different regions, as well as the lack of high-yielding varieties adapted to these conditions.

Our study is aimed at improving the technology of cultivation of plague for seed purposes in order to obtain the maximum seed yield. The aim of the study was to determine the optimal seeding rate and sowing method for the yield of plague seeds in the Lower Volga region of the Russian Federation. 


\section{Methods}

Studies to study the effect of seeding rates and sowing methods on productivity of plague seeds were carried out in the period 2013-2016 at the experimental field of the Federal State Budgetary Scientific Institution of the Russian Research Institute of Sorghum and Crop Rossorgo, which is located in the suburban microzone of the Saratov district, Saratov region on the Volga Upland and geographically located in the southern part of the black earth zone of the Volga region.

The climate of the study area is characterized as sharply continental, arid, with sharply changing weather from year to year. Spring is quite long, giving way to hot, dry summers, winters with little snow and frosty. A stable snow cover forms in the first ten days of December; the average duration of the frost-free period is 160 days. The amplitude of the average annual temperature of the coldest (January) and the warmest (July) month in Saratov is $32.4{ }^{\circ} \mathrm{C}$. During the growing season, an average of $200-230 \mathrm{~mm}$ of precipitation falls.

The weather conditions during the years of studies on temperature, precipitation and distribution of precipitation varied significantly and were characterized by frequent deviations from the average long-term indicators. The sum of active temperatures for the growing season in 2014 and 2015 was 3025.0 and $3020.0^{\circ} \mathrm{C}$, respectively, in 2013 and $2016-2899.0$ and $2955.0^{\circ} \mathrm{C}$. The hydrothermal coefficient was: in 2014 and $2015-0.5$, which refers the zone to dry farming; $2016-0.7$, which classifies the region as a very dry area, in $2013-1.2$ is characterized as a slightly arid zone.

The soil of the experimental field is represented by slightly leached southern shallow chernozem, medium loamy granulometric composition, with a humus content in the arable layer of $3.5 \ldots 3.9 \%$. In terms of nutrient content, the soil is moderately supplied. So, the content of easily hydrolyzable nitrogen was $10 \ldots 15 \mathrm{mg}$, available phosphorus $3.3 \ldots$ $4.0 \mathrm{mg}$, soluble potassium $16 \ldots 22 \mathrm{mg}$ per $100 \mathrm{~g}$ of soil. Therefore, the soil of the experimental field is typical for the zone of dry chernozem steppes in the South-East of Russia.

The material for the study was the plague variety Stachumi 3, which is included in the State Register of Breeding Achievements and approved for use in the region of cultivation.

Cultivation agrotechnics - zonal: developed by scientific institutions of the Lower Volga region. The experiment includes: 54 plots, area of plots 210 and $180 \mathrm{~m} 2$, systematic placement of variants in triplicate. The total area of the experiment is 1.09 hectares. Sowing was carried out in a moist soil layer to a depth of $3-4 \mathrm{~cm}$ with a row spacing of $70 \mathrm{~cm}$ using a SON-4.2 seeder and a row spacing of 15 and $30 \mathrm{~cm}$ using a SZ-3.6 seeder at an optimal time for the growing zone at a soil temperature above $10-12{ }^{\circ} \mathrm{C}$ (second decade May). The predecessor is black fallow. The experiment studied seeding rates from 1.25 to 7.50 million pieces of germinating seeds per hectare, the scheme of the experiment is presented in Table 1.

Table 1. Scheme of the experiment on the study of seeding rates and sowing methods for the productivity of plants of the plague variety Stachumi 3.

\begin{tabular}{|c|c|c|c|}
\hline $\begin{array}{c}\text { Seeding rate }- \text { factor } \mathbf{A}, \\
\text { mln pcs. germinating seeds/ha }\end{array}$ & \multicolumn{3}{|c|}{ Sowing method - factor B, row spacing, cm } \\
\cline { 2 - 4 } & $\mathbf{7 0}$ & $\mathbf{3 0}$ & $\mathbf{1 5}$ \\
\hline 1.25 & + & + & + \\
\hline 2.50 & + & + & + \\
\hline 3.75 & + & + & + \\
\hline 5.00 & + & + & + \\
\hline 6.25 & + & + & + \\
\hline 7.50 & + & + & + \\
\hline
\end{tabular}

Note: + experience option 
The laying and carrying out of the field experiment was carried out in accordance with the methodology of B.A. Dospekhov [14]. The counts and observations were carried out in accordance with the generally accepted methods for conducting field experiments with forage crops [15]. The grain harvest was brought to $14.0 \%$ moisture content and basic conditions for the content of weed and grain impurities.

The statistical analysis of variance of the obtained study results was processed according to the method of B.A. Dospekhov using the AGROS 2.09 software.

\section{Results}

When conducting an experiment, modern mathematical methods are an integral part of the processing and interpretation of the results of the experiment. In our studies, the results obtained are confirmed by the analysis of variance of a two-factor experiment on the study of six gradations of factor $\mathrm{A}$ and three gradations of factor $\mathrm{B}$, according to which significant differences in the effect of the seeding rate on the yield of plague seeds were revealed. In the studies carried out, the action and interaction of the studied factors is significant at the $5 \%$ level. The regularity of a decrease in yield with an increase in the seeding rate to the maximum value in the experiment, as well as a decrease in the studied indicator with a decrease in the row spacing is noted. According to the results of the statistical analysis, the annual influence of the factors "seeding rate" and "seeding method" was revealed. However, on average, over four years of the experiment, the interaction of these factors on each other turned out to be insignificant (Table 2).

Table 2. Results of analysis of variance of the influence of seeding rates and sowing methods on the yield of plague seeds.

\begin{tabular}{|c|c|c|c|c|c|}
\hline \multirow[b]{2}{*}{ Source } & \multicolumn{4}{|c|}{ Years of studies } & \multirow{2}{*}{$\begin{array}{c}\text { On } \\
\text { average } \\
\text { for } 2013- \\
2016\end{array}$} \\
\hline & 2013 & 2014 & 2015 & 2016 & \\
\hline $\mathrm{F}_{\text {fac. factor } \mathrm{A}}$ & $1180.45^{*}$ & $1120.54 *$ & $399.05^{*}$ & $542.54 *$ & $13.45^{*}$ \\
\hline NSR 05 factor $\mathrm{A}$ & 0.08 & 0.04 & 0.06 & 0.05 & 0.41 \\
\hline $\mathrm{ms}$ factor $\mathrm{A}$ & 6.88 & 1.63 & 1.44 & 0.99 & 2.99 \\
\hline$F_{\text {fac. factor } B}$ & $173.50^{*}$ & $126.87^{*}$ & $149.70^{*}$ & $1533.42 *$ & $20.01 *$ \\
\hline NSR 05 factor $B$ & 0.07 & 0.04 & 0.05 & 0.04 & 0.18 \\
\hline $\mathrm{ms}$ factor $\mathrm{B}$ & 1.85 & 0.41 & 0.64 & 5.26 & 1.90 \\
\hline $\mathrm{F}_{\text {fac. interaction } \mathrm{AB}}$ & $52.79 *$ & $32.27 *$ & $15.02 *$ & $37.89^{*}$ & 1.18 \\
\hline NSR 05 interaction $\mathrm{AB}$ & 0.16 & 0.09 & 0.11 & 0.09 & ns \\
\hline $\mathrm{ms}$ factor $\mathrm{AB}$ & 0.56 & 0.10 & 0.06 & 0.13 & 0.11 \\
\hline
\end{tabular}

Note: ${ }^{*}$ - the degree of confidence at the $0.05 \%$ significance level, ns - not significant. Based on the results of analysis of variance of field experience data, the significant significance of the factors under study was established and their different effects were noted on the yield of plague seeds. Wherein, the main share in the manifestation of a trait over three years of study is made by factor A (seeding rate), here the variation of repetitions accounts for a significant part of the total variation $-7.19-8.15$, which is $77.6-80.7 \%$ of the total the sum of squares, and only in 2016 the share of the influence of this factor was $29.5 \%$ only. Factor B (sowing method) in 2013, 2014 and 2015 accounted for from $8.0 \%$ to $13.8 \%$, and in 2016 the share of the studied factor increased to $62.1 \%$ (Figure 1 ).

It shall be noted that the share of the interaction of $\mathrm{AB}$ factors over the years of study varied slightly from $6.9 \%$ to $10.2 \%$. On average, over the four years of the experiment, factor A - seeding rate - was $47.5 \%$, and factor B - seeding method -only $12.1 \%$. 
Wherein, the variance of the error (residual) was $36.9 \%$, which is due to the variability of the data obtained over the years.

According to the study results, the maximum yield of plague grain was noted in the most favorable year in terms of moisture in 2013 with wide-row sowing with a row spacing of 70 and $30 \mathrm{~cm}$ and a plant density of 1.25 and 2.50 million $\mathrm{pcs} / \mathrm{ha}-2.91$ and $3.81 \mathrm{tons} / \mathrm{ha}$, respectively. With an increase in the number of plants per unit area to the maximum indicators (7.50 million pcs./ha), inhibition of plants was noted and, as a consequence, a decrease in grain yield by $75.6 \%$ and $82.7 \%$. It shall be noted that the plague with a widerow sowing method turned out to be more productive than with a row sowing (Table 3 ).

On average, over four years, the maximum grain yield was obtained with a wide-row sowing method $(70 \mathrm{~cm})$ and a seeding rate of 1.25 million $\mathrm{pcs} . / \mathrm{ha}$, and when sowing with a row spacing of $30 \mathrm{~cm}$, the most productive was the seeding rate of 2.50 million pcs./ha $(1.43 \mathrm{t} / \mathrm{ha})$, with a decrease in the row spacing to $15 \mathrm{~cm}$ at the same seeding rate, the yield decreased by $56.8 \%$.
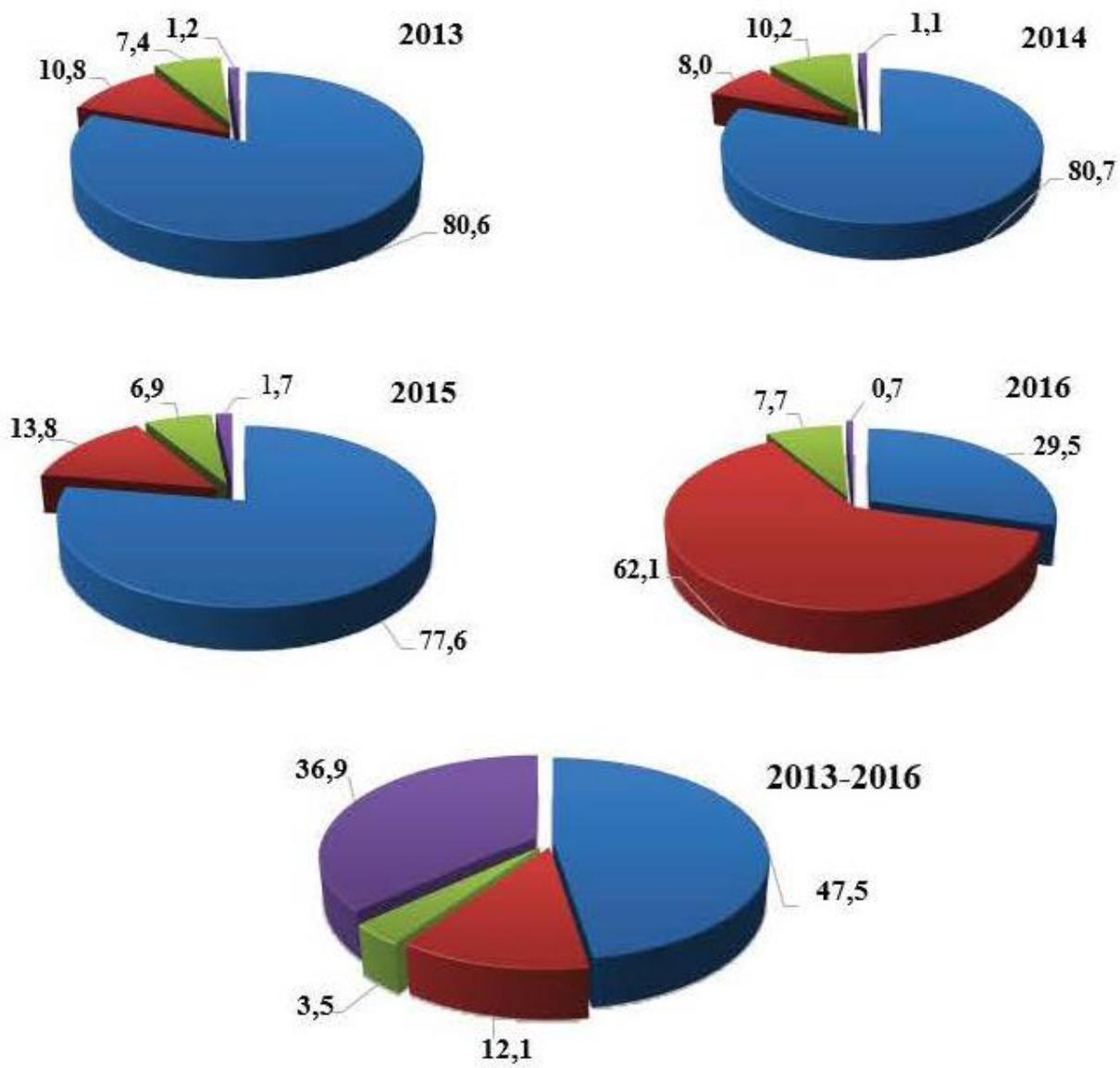

Factor $\mathrm{A}$ Factor $\mathrm{B}$ Interaction $\mathrm{AB}$ Residual

Fig. 1. The share of the influence of seeding rate factors (factor A) and sowing methods (factor B) and their interaction on the yield of plague seeds by years of study, $\%$. 
Table 3. Influence of sowing methods and seeding rates on the yield of plague grain, $\mathrm{t} / \mathrm{ha}$.

\begin{tabular}{|c|c|c|c|c|c|c|}
\hline \multirow[b]{2}{*}{$\begin{array}{c}\text { Seeding rate } \\
\text { - factor } A \text {, } \\
\text { mln pcs./ha }\end{array}$} & \multirow[b]{2}{*}{$\begin{array}{c}\text { Sowing method factor } \\
\text { B }\end{array}$} & \multicolumn{4}{|c|}{ Years of studies } & \multirow{2}{*}{$\begin{array}{c}\text { On } \\
\text { average } \\
\text { for } \\
2013- \\
2016\end{array}$} \\
\hline & & 2013 & 2014 & 2015 & 2016 & \\
\hline 1.25 & \multirow{6}{*}{$\begin{array}{l}\text { wide-row sowing with } \\
70 \mathrm{~cm} \text { row spacing }\end{array}$} & 2.91 & 1.42 & 1.89 & 2.31 & 2.13 \\
\hline 2.50 & & 2.89 & 1.23 & 1.51 & 1.89 & 1.88 \\
\hline 3.75 & & 1.44 & 0.91 & 1.40 & 1.44 & 1.31 \\
\hline 5.00 & & 1.13 & 0.90 & 1.00 & 1.17 & 1.05 \\
\hline 6.25 & & 0.93 & 0.57 & 0.89 & 1.22 & 0.90 \\
\hline 7.50 & & 0.71 & 0.55 & 0.80 & 0.82 & 0.72 \\
\hline \multicolumn{2}{|c|}{ average for factor B } & $1.67 \mathrm{~b}$ & $0.93 \mathrm{c}$ & $1.25 \mathrm{c}$ & $1.48 \mathrm{c}$ & $1.33 \mathrm{c}$ \\
\hline 1.25 & \multirow{6}{*}{$\begin{array}{l}\text { wide-row sowing with } \\
30 \mathrm{~cm} \text { row spacing }\end{array}$} & 2.20 & 1.92 & 1.58 & 0.90 & 1.65 \\
\hline 2.50 & & 3.81 & 1.21 & 1.61 & 1.08 & 1.43 \\
\hline 3.75 & & 1.30 & 0.63 & 1.10 & 0.76 & 0.95 \\
\hline 5.00 & & 1.08 & 0.58 & 0.81 & 0.54 & 0.75 \\
\hline 6.25 & & 0.82 & 0.46 & 0.52 & 0.38 & 0.55 \\
\hline 7.50 & & 0.66 & 0.39 & 0.46 & 0.29 & 0.45 \\
\hline \multicolumn{2}{|c|}{ average for factor B } & $1.64 \mathrm{~b}$ & $0.86 \mathrm{~b}$ & $1.01 \mathrm{~b}$ & $0.66 \mathrm{~b}$ & $1.05 \mathrm{~b}$ \\
\hline 1.25 & \multirow{6}{*}{$\begin{array}{l}\text { row sowing with } \\
\text { row spacing of } 15 \mathrm{~cm}\end{array}$} & 1.85 & 1.08 & 1.25 & 0.64 & 1.21 \\
\hline 2.50 & & 1.64 & 1.04 & 1.14 & 0.71 & 1.13 \\
\hline 3.75 & & 1.06 & 0.77 & 0.91 & 0.43 & 0.79 \\
\hline 5.00 & & 0.86 & 0.46 & 0.77 & 0.39 & 0.62 \\
\hline 6.25 & & 0.67 & 0.28 & 0.77 & 0.30 & 0.51 \\
\hline 7.50 & & 0.52 & 0.23 & 0.42 & 0.25 & 0.36 \\
\hline \multicolumn{2}{|c|}{ average for factor $\mathrm{B}$} & $1.10 \mathrm{a}$ & $0.64 \mathrm{a}$ & $0.88 \mathrm{a}$ & $0.45 \mathrm{a}$ & $0.77 \mathrm{a}$ \\
\hline
\end{tabular}

Note: the data in the columns for factor B for each year, denoted by different letters, are significantly different from each other, according to Duncan's multiple comparisons test.

Multiple comparisons of private means according to Duncan's rank test showed significant differences between the seeding rates studied in the experiment. The significance of the influence of factor $\mathrm{A}$ is assessed in accordance with the analysis of variance model with different Latin letter values, which indicates the corresponding variants of the experience significantly differing from each other. It shall be noted that the greatest difference was noted in the most favorable year in terms of meteorological conditions in 2013 with a seeding rate of 2.50 million pcs./ha and amounted to $2.78 \mathrm{t} / \mathrm{ha}$. Analysis of variance made it possible to reveal significant differences between the studied variants of the experiment and made it possible to establish a clear pattern of a decrease in the yield of plague seeds with an increase in the seeding rate to maximum values 7.50 million pcs./ha, according to average annual indicators, it was $0.51 \mathrm{t} / \mathrm{ha}$ (Figure 2).

\section{Discussion}

In our study, the optimal seeding rate and method of sowing plague was established in order to obtain the maximum seed yield. An important condition for ensuring the efficiency of production in agriculture is to obtain the maximum yield of agricultural crops. Productivity is the main factor that determines the volume of crop production, therefore, much attention is paid to this indicator. Formation of the biological yield of plague in our studies largely depended on the growing conditions, the seeding rate and the method of sowing. 
Analyzing the results of work aimed at obtaining the maximum possible yield of plague seeds, we, first of all, refere to the productivity indicators per unit of sown area. The proper planting density, on which the number of plants per hectare depends, is one of the most important conditions for obtaining a high yield. Therefore, the number of plants per unit area shall not be lower than a certain level, and the largest yield is obtained not with the maximum possible one, but with a known optimal number of plants per unit of sown area and with their optimal combination. So, for example, excessive thickening usually causes mutual inhibition of plants and a decrease in yield, which was noted as a result of the field experiment, and also noted in the papers of other scientists, including the papers of S.V. Letuchiy and Gupta A. et al.
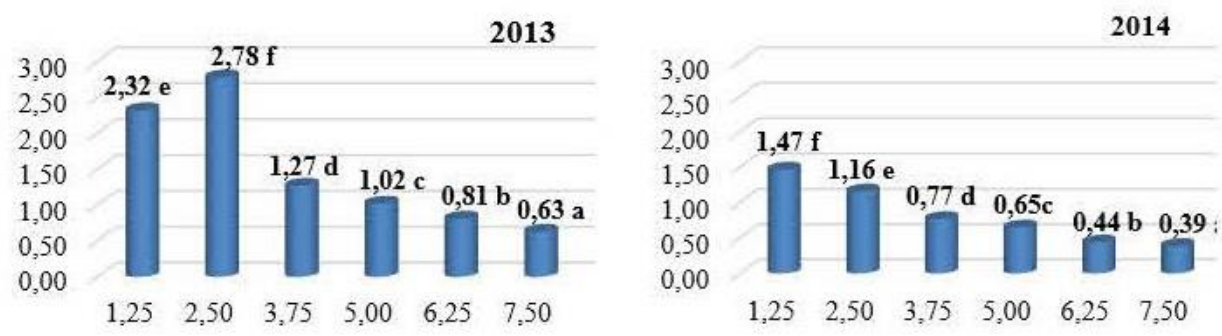

2015
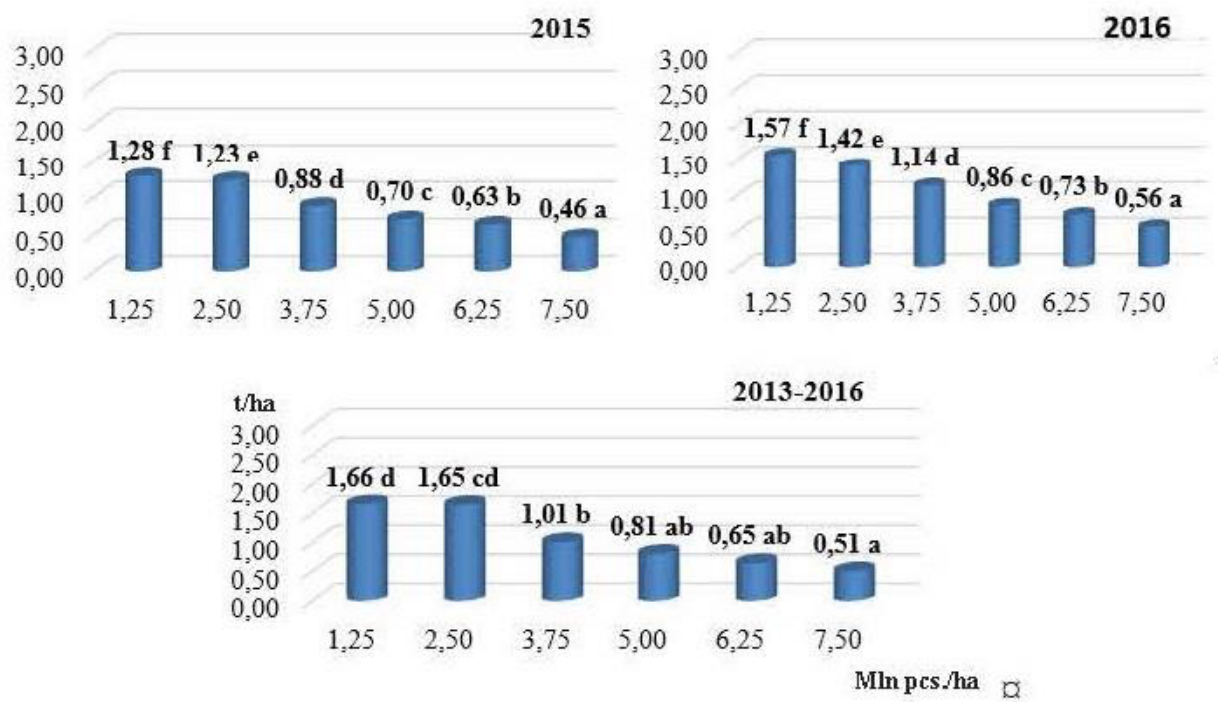

Fig. 2. Multiple comparisons of private average yields of plague grain by factor A (seeding rates) over the years of study.

\section{Conclusion}

The soil and climatic conditions of the Saratov Right Bank, subject to the optimal cultivation technology, allow, in dry conditions, to obtain a yield of plague seeds of 2.91 $3.81 \mathrm{t} / \mathrm{ha}$. Analyzing the results of the experiments, the following pattern is observed: with an increase in the seeding rate to the maximum in the experiment ( 7.50 million pcs./ha), a tendency for a decrease in seed yield was noted with all the studied sowing methods, as well as with a decrease in the row spacing to $15 \mathrm{~cm}$, a similar pattern of yield decline. The highest yield in the experiment was obtained at a seeding rate of 2.50 million pcs./ha with a 
wide-row sowing method (row spacing of $30 \mathrm{~cm}$ ) $-3.81 \mathrm{t} / \mathrm{ha}$, a further increase in the seeding rate led to a decrease in the yield of plague seeds. The lowest yield in the experiment over the years of study was obtained at a seeding rate of 7.50 million pcs./ha for all the studied sowing methods.

\section{References}

1. O.P. Kibal'nik, I.G. Yefremova, D.S. Semin, Grain farming in Russia, 64, 4 (2019)

2. T. Avetisyan, L. P. Baykalova, O.S. Artemyev, O. V. Martynova, IOP Conf. Series: Earth and Environmental Science, 548 (2020)

3. E.A. Vertikova, In the World of Scientific Discoveries, 81, 8 (2016)

4. I.A. Donets, M.P. Zhukova, A.B. Volodin, Bulletin of Agroindustrial Complex of Stavropol, 35, 3 (2019)

5. M.K. Sadygova, T.I. Anikienko, O.S. Bashinskaya, Journal of Ernahrung, 43, 3 (2019)

6. L.I. Kuznetsova, M.K. Sadygova, O.S. Bashinskaya, V.I. Zhuzhukin, Pat. 2018117123 Rossiyskaya Federatsiya, № RU 2694591 C1 (2019)

7. S. Sakamoto, JARQ, 21, 2 (1987)

8. H. Darmency, In Crop Ferality and Volunteerism (CRC Press, Boca Raton, 2005)

9. V.I. Zotikov, Legumes and cereals, 35, 3 (2020)

10. Gupta, R.-M. Andrés, A.I. Cao-Delgado, Science, 6488, 368 (2020)

11. H. Jiang, T. Thobakgale, Y. Li, L. Liu, Q. Su, B. Cang, C. Bai, J. Li, Z. Song, M. Wu, D. Wang, J. Cui, Scientific Reports, 3, 11 (2021)

12. R.M. Vasilenko, Feed production, 6 (2014)

13. S.V. Letuchiy (Abstract of dis. ... Candidate of Agricultural Sciences: 06.01.09, 2009)

14. B.A. Dospekhov, Alliance (Moscow, 2014)

15. Methodology of state variety testing of agricultural crops (2019) 